\title{
Enhancing the learning of multi-level undergraduate Chinese language with a 3D immersive experience - An exploratory study
}

\author{
Yanjun Wang, Scott Grant, and Matthew Grist ${ }^{1}$
}

\section{ABSTRACT}

The article reports on a study that incorporated an immersive 3D virtual environment, created in Second Life (SL) into the curriculum of a Chinese program, including its development, implementation and evaluation. This innovation supplemented classroom teaching of Chinese language throughout one semester at a regional Australian university. Using the existing resource called Chinese Island $(\mathrm{Cl})^{2}$ created by a major urban Australian university, the primary aim of this study was to probe student's perceptions about the resource. Due to curriculum differences between two universities, customised language and culture learning tasks based on the learnt textbook content were designed on $\mathrm{Cl}$, with instructions and associated quizzes hosted in a private Moodle site-a widely-used learning management system (LMS) environment. Twenty-eight mixedlevel undergraduate Chinese as a foreign language (CFL) students participated in a survey, and seven of these students were interviewed. The questionnaire and interview data were collected and analysed during the study. Following analysis, results indicated that students welcomed the experiential learning opportunity to explore Chinese culture and language outside the classroom afforded by $\mathrm{Cl}$. Anecdotal evidence suggested that students became more aware of the complicated pragmatic issues in real life communication. The survey results, including the participants' responses to open-ended questions, are discussed in this paper. Pedagogical implications and directions for further research are also considered.

\section{KEYWORDS}

Chinese as a foreign language (CFL); immersive 3D virtual environment; Second Life (SL); experiential learning; foreign language classroom

\section{Introduction}

Learning a foreign language is widely acknowledged to be a difficult and time-consuming task (Johnson, 2008), and Chinese is often mentioned as being a particularly challenging language for native speakers of English to learn (Orton, 2010). In the past decade, the global spread of Chinese as a foreign language (CFL) has required educators to diversify their pedagogy in order to be effective in many different educational contexts, and in common with the teaching of all foreign languages, CFL teachers and learners are being transformed by mobility, technologies, and information networks (Moloney \& Xu, 2016). In addition, the continuing decrease in non-Chinese background students studying Chinese at Australian schools suggests a major challenge as well as an important role for educators in re-engaging students, promoting the value of Chinese language proficiency, and sharing ideas across the sectors (Pasfield-Neofitou, Grant, \& Huang, 2016). In the quest to respond to this challenging environment-especially to increase the number of opportunities to hear and use language in real situations (Orton, 2010) -this study introduced a virtual world (VW) environment, Chinese Island $(\mathrm{Cl})$, to the undergraduate Chinese program at a regional Australian university. This environment more closely resembles the "real world" than a traditional classroom (Lan \& Ling,

\footnotetext{
${ }^{1}$ Y. Wang and M. Grist, University of Tasmania, Launceston, Australia email: yanjun.wang@utas.edu.au; matthew.grist@utas.edu.au;

S. Grant, University of Monash, Melbourne, Australia, email: scott.grant@monash.edu

${ }^{2}$ https://www.youtube.com/watch?v=1LOEX--dqZA
} 
2016), as students can model communicative behaviours in real life by interacting with each other as well as with Non-Player Characters (NPCs) on Cl. The purpose was to effectively engage CFL students and enhance their learning experience through the provision of this additional learning opportunity, specifically through facilitating authentic language use in a way that draws on students' cognitive engagement for the purpose of making meaning with language (Thomas \& Reinders, 2012), rather than through traditional memorisation and rote learning strategies. The ultimate goal of the study was to identify appropriate ways to use SL to enhance student learning (Chen, 2010).

\section{Context of the Study}

This section will depict the context of the study by outlining some background information, particularly with a focus on the challenges that foreign language programs face at this regional university, mainly in relation to geographic isolation, curriculum constraints, and multi-campus delivery modes (including online).

Firstly, foreign language learners in a classroom environment, especially in locations where that language is not frequently used, often lack the opportunity for immersion in the target language. It is particularly challenging for foreign language teaching and learning at this regional university as, geographically speaking, the region is not in close association with any proximate foreign language community. Research shows that students' reluctance to continue language study is due to many factors, prominent among which is the lack of access to opportunities to develop communicative competence (Hymes, 1992). Secondly, CFL education generally has struggled with low contact hours and budgetary constraints affecting the quality of learning and teaching and proficiency outcomes (Group of Eight, 2007). Further, the interactions students practice in the language classroom are quite limited and artificial, and this in turn limits the students' long-term learning (Scarino \& Liddicoat, 2009). Thirdly, in this century, apart from helping to increase learners' access to foreign language education, technology advancement encourages self-learning and lifelong learning "since the mastery of the subject may not be achieved without immersing oneself in authentic language environment outside of the classroom" (Navarre, 2019, p. 9). In addition, there is ample evidence that communication in a foreign language in an e-learning environment is less stressful or threatening to learners than face-to-face (F2F) settings (Casanave, 2004; Chun, 1998; Grant, Huang, \& Pasfield-Neofitou, 2013; Rubesch \& McNeil, 2010). In terms of this study, technology enabled foreign language teaching and learning at this university to gradually shift from a traditional F2F teaching mode to a contemporary, blended mode by integrating a wide range of sophisticated online learning resources. One example was the successful online implementation of four introductory level language units (Chinese, Indonesian, Japanese, and German) allowing for fully online study across all campuses. Meanwhile this initiative created challenges in language teaching due to online students' limited opportunity to engage with the course content and other fellow students. In addition, there has been an increasing demand on the use of target languages in a reallife and meaningful context.

University study should prepare students to apply their acquired knowledge to real-world problems. Consequently, with respect to the challenges already discussed, this study aimed to address the difficulties students have in accessing immersive environments in the target language. Given the priority for developing learners' communicative capability in Chinese (Orton \& Scrimgeour, 2019), and with a view to enhancing the learning experience for multi-campus and distance cohorts, it was considered crucial to provide a platform for immersion and opportunities for interaction in contextualised tasks. From another perspective, the $\mathrm{Cl}$ platform also focused its attention on the "Zone of Proximal Development" (ZPD), in which progress can be made in language acquisition through "socially mediated interaction" (Brown, 2000). Additionally, this study was based on an 
ongoing research collaboration between two universities, both extending the use of this resource and fostering a community of practice in order to ensure its sustainable and ongoing development (Pasfield-Neofitou et al., 2016).

\section{Literature review}

\section{Features of experiential learning}

Experiential learning is a well-established approach to learning at tertiary level (Schott \& Marshall, 2018) that emphasises the process of knowledge creation through the transformation of experience, where the process results in new knowledge (Burch et al., 2019). Kolb (2014) highlights three aspects of experiential learning as being fundamental to this approach and different from other approaches: rather than defining learning in terms of its outcomes, there is an emphasis on the process of adaptation and learning; knowledge is continually created and re-created through experience as part of an ongoing transformation process, rather than being fixed and immutable and transmitted to and acquired by the learner; and thirdly, understanding learning requires an understanding of the nature of knowledge and vice versa. Further, Kolb sees the learning process being facilitated by "bringing out the learner's beliefs and theories, examining and testing them, and then integrating the new, more refined ideas into the person's belief systems." (2014, p. 39)

While Kolb emphasised the focus of experiential learning as not being on "outcomes", Burch et al. (2019) have argued that increasing students' learning has been a goal of many educators using this approach over the years. More often than not, measuring any increase relies on examining learning outcomes, yet there has been a lack of research definitively demonstrating the overall effectiveness of the approach in achieving concrete outcomes. With this in mind, Burch et al. examined 89 studies on experiential learning across a 43-year timespan. The results of their meta-analysis definitively and quantitatively affirmed the efficacy of experiential learning in terms of delivering superior learning outcomes and that this efficacy is robust across a range of learning outcomes relevant to higher education. Their analysis revealed particular benefits for social and cognitive development, but less so for personal insight. Sharifi and Shariati (2017) conducted a controlled experiment with elementary students in Iran looking at differences in outcomes between a traditional learning approach to learning English as a foreign language and an experiential learning approach. Analysis of data collected during the experiment showed that although both groups of students started from a similar level, the experiential learning group achieved grades significantly better than the control group.

\section{Challenges associated with experiential learning}

While there are benefits of experiential learning, it is not free of its own challenges. For learners who are not familiar with the approach, experiential learning can seem confusing and unfocused. Kolb, in relating his own awakening to the potential of experiential learning during a T-group training session many years ago, commented that:

While some students and trainees "got it" and were as profoundly influenced by their experience as I was, for many it was more about "emotional intelligence" than they were ready for. The lack of structure and deviation from the traditional classroom learning process they were accustomed to was too confusing for them to get much from the unstructured groups. (Kolb, 2014, p. xvii)

Knutson (2003) argued, however, that one of the "thorniest" problems faced by educators implementing experiential learning in their classroom is assessment. In the area of foreign language 
learning, learners facing the prospect of an exam need an accurate assessment of their progress, and Knutson maintained that the self-evaluation that often forms part of experiential learning is not always helpful. She did, however, see an important role for rubric-style evaluation of employability skills, such as teamwork and leadership, and language skills, such as oral proficiency. Austin and Rust (2015) in their review of the development of an experiential learning program at a state university in the US, found that while developing learning outcomes was relatively easy, determining exactly how to measure such outcomes and design appropriate rubrics was challenging.

\section{The need to move beyond the classroom and technology}

Some researchers have emphasised the need for raising learner awareness about the importance of learning outside the classroom, and encouraging learners to move beyond the "confines of the pedagogic environment" of the classroom, self-access centre, and the school, to integrate new knowledge into their lives (Reinders, 2010, p. 48). In researching pedagogical approaches to the teaching of clinical practice in the traditional tertiary classroom, Brannan, White, and Bezanson (2008) observed that the traditional classroom lecture mostly cannot provide a means for implementing the experiential learning required for clinical practice. Providing learners with opportunities for experiential learning within the framework of a traditional tertiary level curriculum has also been an ongoing challenge.

However, the rapid development of digital technology has provided new opportunities for implementing experiential learning. Schott and Marshall saw digital technology as providing "ever more sophisticated prospects to foster experiential learning" (2018, p. 843). As part of their overall findings into the efficacy of experiential learning for increasing student learning, Burch et al. specifically found that experiential learning activities that included a simulation outperformed exercises that did not include simulation $(2019$, p. 254). Moreover, in the specific area of secondlanguage instruction, Blake (2017) pointed out that the use of technology is becoming commonplace, whether in support of traditional, blended, or fully online formats.

\section{Experiential learning in the foreign language classroom}

At its core, experiential learning can be viewed as a continuous cycle that involves engaging in an experience using existing skills and knowledge, reflecting on that experience, conceptualising insights gained from that reflection, and then applying the newly learned concepts as part of an ongoing process of new knowledge and skill building. Kohonen (1992) argued that experiential learning in the foreign language classroom can be justified on the basis of four considerations: facilitating personal growth; helping learners to adapt to social change; taking account of differences in learning abilities; and responding to the needs of learners and practical pedagogical considerations (p. 48). Kohonen further argued that there are three areas of knowledge and awareness in experiential learning that supplement each other: personal growth; the learning process; and the learning task (p. 51). The experiential learning cycle, the three areas of knowledge and awareness, and the resulting areas of increased learner awareness are clearly illustrated in Figure 1.

Kohonen argued that intrinsic motivation is a key ingredient in successful learning, and that a sense of competence is key to motivation. Enhancing the three areas of knowledge and awareness for learners is an important factor in establishing a sense of competence and, therefore, increasing intrinsic motivation. Other characteristics that are crucial to a sense of competence in language learning include: a tolerance to unpredictability, novelty, and insolubility that comes with learning a 
new linguistic system, and thus dealing with the unknown; ambiguity, and making mistakes with equanimity (p. 52); and autonomy and self-direction of the learning process (Reinders, 2010, p. 40).

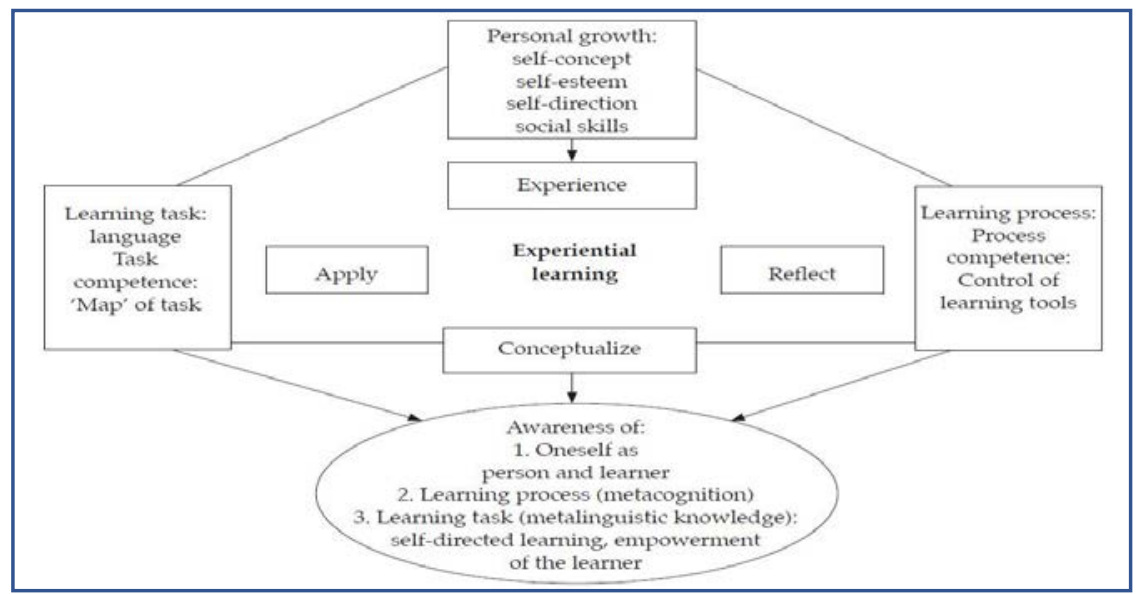

Figure 1. Experiential learning cycle (Kohonen, 1992)

Enhancing a learner's knowledge and awareness of all these aspects of learning can be empowering. Lopez et. al (Moreno-López, Ramos-Sellman, Miranda-Aldaco, \& Gomis Quinto, 2017) found that college students studying Spanish as a foreign language reported that their motivation to learn (and to continue on to higher levels of learning), confidence with using the language, and curiosity about cultural differences and similarities was enhanced by the addition of experiential components to their classroom learning.

\section{Experiential learning in virtual world environments}

For nearly two decades, the potential of 3D multiuser virtual worlds (3D MUVWs)-like Second Life (SL)-as educational environments suited to a range of pedagogical approaches has attracted the interest of researchers and educators from a wide range of disciplines. Jarmon Traphagan, Mayrath, and Trivedi (2009) pointed out that many educational practices lack opportunities for students to experiment with what they learn, and their creativity in the world outside the classroom. They put this down to the many constraints that the real world imposes on the creation of experiential learning environments. Based on the extant literature at the time, they argued that, in contrast, open 3D MUVWs, like SL, "provide an environment supportive of learning activities such as experimentation, exploration, task selection, creation, and dynamic feedback" (p. 170). In this light, they conducted a study designed to examine the instructional effectiveness of SL as an experiential learning environment in a graduate interdisciplinary communication course. Six characteristics that foster experiential learning emerged from learner feedback from the study: the ability to engage in social interactions and collaboration; the ability to test hypotheses by applying them to an actual project, and implementing actions without the risks and cost of the real world; the potential relevance of their virtual actions to the real world; the possibility of practising various types of abilities and demonstrating them virtually; being stimulated by imagination, exploration, and creativity; and a strong sense of presence and visceral experience in the virtual environment. Reinders (2010) argued that the study of a foreign language requires the ability to experiment with the language and to take risks. Jarmon et al.'s study demonstrated the effectiveness of the SL environment for a project-based experiential learning approach, particularly as students were able to learn by doing and by applying learned concepts to the real world (p. 178).

A study by Machado, Klein, Freitas, Schlemmer, and Pedron (2016) involving 92 Master students from Brazil and Portugal who engaged in a series of activities for collaborative work has shown that 
3D MUVWs like SL can also be used for the development of intercultural communication because they allow rich experiential and relational / conversational learning opportunities, especially due to the affordances of immersion / sense of presence, social interaction, content production and knowledge sharing.

\section{Method}

\section{Research questions}

The following questions are phrased around the specific program being investigated, but also have relevance for other similar programs that make use of 3D MUVWs. They were:

1. Is the integration of $\mathrm{Cl}$ into the Chinese program feasible and justifiable?

2. Do students welcome the use of $\mathrm{Cl}$ as an additional learning resource?

3. In what ways does $\mathrm{Cl}$ enrich students' learning experiences?

\section{Participants}

Participants $(N=28)$ were drawn from the body of currently enrolled students in the CFL program at this regional Australian university, including students from all stages of the program. Sixty-four percent ( $n=18$ ) were female, with the remaining $36 \%$ being male. The majority of students $(79 \%, n$ $=22)$ were under 30 years of age, but $14 \%(n=4)$ were aged 46 years or over. Ninety-three percent $(n=26)$ studied on-campus, while $7 \%(n=2)$ students studied in off-campus delivery mode. Most students $(86 \%, n=24)$ were enrolled on a full-time basis. Thirty-nine percent $(n=11)$ of respondents indicated a high level of engagement in multiplayer online computer games, with a further $18 \%$ ( $n=$ 5 ) reporting familiarity with offline computer gaming, while the remaining $43 \%(n=12)$ students indicated a minimal familiarity with computer gaming. Most students had access to high-speed broadband internet at home, apart from one respondent who indicated their home internet connection was "very slow" (satellite or dial-up speed).

All students-who at the time were enrolled in any Chinese language unit designed for foreign language learners at the university-were provided with access to a non-compulsory, extracurricular, online activity space based on the principles of Task-Based Language Learning (TBLL). This activity space comprised two components-a custom-built area $(\mathrm{Cl})$ within the publicly-available immersive 3D online simulation "SL," and a custom-built website "Virtual Chinese" via Moodle, containing materials such as technical instructions, language quizzes, and direct access links to locations within $\mathrm{Cl}$. Participants in the research were recruited from among those students who had exhibited some degree of interest in this voluntary online learning activity.

All participants were volunteers, and the size of the pool of potential participants was not large enough to provide the researchers with the opportunity to select participants from among those volunteers, so the issue of sample bias was considered. Although this recruitment method tends to attract only respondents who have a "strong interest in the topic" (Tranter, 2013), the impact of sample bias was considered to be low, since all survey invitees already answered to that description in virtue of the fact that in order to be eligible, they had to have shown sufficient interest in the optional extension task offered to all students in the Chinese program.

\section{Research design}

Previous research undertaken in CFL through SL software had found that students" "technical competency" with navigating 3D virtual spaces needed to be built up intentionally as a part of curriculum delivery, in order for students' confidence levels to be bolstered against the complexity 
of the (to some) unfamiliar environment (Chen, 2010). Otherwise, performance improvements could not be expected (Henderson, Huang, Grant, \& Henderson, 2012, p. 412). The present study, by contrast, deployed SL alongside a dashboard-style website as an optional extension activity. Moreover, the study was not measuring changes in student variables, but examining student experience. As such, it was not pedagogically appropriate to provide extensive technical instruction through the classroom setting, and, instead, this was offered in a more self-service delivery mode via Virtual Chinese. This approach, in turn, enabled the focus of the investigation to widen beyond solely those elements of $\mathrm{Cl}$ that might have been used in a given learning or assessment activity, and to gain insight into how students viewed the affordances of the technology-to discover, in other words, what aspects stood out for them as being most beneficial.

Furthermore, as has been discussed, this study was conducted in a regional location with a relatively dispersed population, so the researchers were particularly interested in how the technologies might be received by students in remote localities, including those students who might be studying by distance delivery modes. With this in mind, "how-to" information was provided by email and on discussion boards. Support sessions were also arranged in video conferencing. In class, however, the approach taken was just to demonstrate some of the capabilities of the software, so as to pique students' interest in exploring $\mathrm{Cl}$ for themselves.

After eight weeks of availability, students who had tried $\mathrm{Cl}$ were invited to participate in a survey that sought both quantitative and qualitative data about them and their experiences with the online space. Survey respondents were invited to take part in individual or focus group interviews, during which further qualitative data were collected. Quantitative data were subjected to basic statistical analysis, and qualitative data were analysed using thematic analysis.

\section{Instrument}

The survey instrument was a questionnaire that consisted, primarily, of multiple-choice questions that sought quantitative and demographic data, and one question that permitted the selection of more than one option. The first eight questions sought information about the students, such as demographics, their level of familiarity with computer technologies, their study status, and motivations. Questions 9 to 15 asked about their experience in $\mathrm{Cl}$ and represented the core of the quantitative data collected-making use of a five-point Likert-style scale (plus an option for "not applicable") by which the respondents' level of agreement with a statement was expressed. There was also an open-ended question asking students if there was anything specific, they wanted to tell the researchers about their experience.

This last question was the primary source of the qualitative data collected by the survey. However, while questions 9 to 15 were couched in quantifiable terms, the information collected was also used in qualitative data analysis, as explained below. The boundary between qualitative and quantitative analysis is in any case porous in this investigation, since much of its subject matter pertains to subjective aspects of user experience in $\mathrm{Cl}$.

The full set of questions asked in the survey is available by email request to the corresponding author. The survey was made available in both electronic and printed form, and the responses from the seven paper copies received were transcribed and amalgamated with the submissions received electronically.

\section{Results}

Approval and frustrations 
The survey contained five questions designed to measure to what degree the respondents approved of $\mathrm{Cl}$, with three questions phrased so that agreement would indicate approval (e.g., "I could see how the activities and tasks were helping me learn Chinese") and two phrased so that disagreement would suggest approval (e.g., "There was too much new material in the language tasks"). The responses for these five questions were aggregated to produce a single value indicating how positive each participant's overall response to $\mathrm{Cl}$ was.

Two further questions probed the extent of any difficulties users may have experienced (e.g., "I had trouble getting my computer ready to use $\mathrm{Cl}^{\prime \prime}$ ). Any participant who expressed strong agreement with either of these questions, or moderate agreement with both, was classified as having experienced frustration. Comments made in the open-ended question were also examined for indications of technical frustrations. This process produced a binary value for whether a participant expressed frustration with $\mathrm{Cl}$. Six respondents met these criteria, and among these six, were the only three respondents whose approval rating was negative. It is also encouraging to note that the other three students who experienced difficulties in getting set up were still favourable in their impressions after, in the end, having been able to overcome these issues.

These two measures provide digestible, "at-a-glance" views on the data reported in Table 1 below and were deployed because the sample size did not permit meaningful comparisons at the level of individual items.

Table 1. Survey results

\begin{tabular}{|c|c|c|c|c|c|c|c|c|c|}
\hline Item & & SA & $\bar{A}$ & NS & D & SD & NA & Total & Mean \\
\hline \multirow{2}{*}{$\begin{array}{l}\text { Q1. I could see how the activities } \\
\text { and tasks were helping me to } \\
\text { learn Chinese. }\end{array}$} & Count & 8 & 7 & 3 & 1 & 2 & 3 & 24 & \multirow[t]{2}{*}{4.13} \\
\hline & $\%$ of total & 33.33 & 29.17 & 12.5 & 4.17 & 8.33 & 12.5 & $100 \%$ & \\
\hline \multirow{2}{*}{$\begin{array}{l}\text { Q2. After using Chinese Island, } \\
\text { the idea of further Chinese study } \\
\text { seems less daunting. }\end{array}$} & Count & 1 & 9 & 5 & 2 & 2 & 5 & 24 & \multirow[t]{2}{*}{3.83} \\
\hline & $\%$ of total & 4.17 & 37.5 & 20.83 & 8.33 & 8.33 & 20.83 & $100 \%$ & \\
\hline \multirow{2}{*}{$\begin{array}{l}\text { Q3. I would like to further } \\
\text { explore Chinese Island if it } \\
\text { continues to be available. }\end{array}$} & Count & 10 & 8 & 2 & 0 & 2 & 2 & 24 & \multirow[t]{2}{*}{4.25} \\
\hline & $\%$ of total & 41.67 & 33.33 & 8.33 & 0 & 8.33 & 8.33 & $100 \%$ & \\
\hline \multirow{2}{*}{$\begin{array}{l}\text { Q4. There was too much new } \\
\text { material in the language tasks. }\end{array}$} & Count & 0 & 4 & 5 & 7 & 4 & 4 & 24 & \multirow[t]{2}{*}{3.04} \\
\hline & $\%$ of total & 0 & 16.67 & 20.83 & 29.17 & 16.67 & 16.67 & $100 \%$ & \\
\hline \multirow{2}{*}{$\begin{array}{l}\text { Q5. I felt awkward or } \\
\text { embarrassed about interacting } \\
\text { with the characters/other } \\
\text { players. }\end{array}$} & Count & 1 & 3 & 4 & 3 & 8 & 5 & 24 & \multirow[t]{2}{*}{3.04} \\
\hline & $\%$ of total & 4.17 & 12.5 & 16.67 & 12.5 & 33.33 & 20.83 & $100 \%$ & \\
\hline \multirow{2}{*}{$\begin{array}{l}\text { Q6. I had trouble getting my } \\
\text { computer ready to use Chinese } \\
\text { Island. }\end{array}$} & Count & 1 & 6 & 4 & 7 & 3 & 0 & 21 & \multirow[t]{2}{*}{2.76} \\
\hline & $\%$ of total & 4.76 & 28.57 & 19.05 & 33.33 & 14.29 & 0 & $100 \%$ & \\
\hline \multirow{2}{*}{$\begin{array}{l}\text { Q7. It was sometimes hard to } \\
\text { make my avatar do what I } \\
\text { wanted. }\end{array}$} & Count & 3 & 6 & 3 & 8 & 1 & 3 & 24 & \multirow[t]{2}{*}{3.46} \\
\hline & $\%$ of total & 12.5 & 25 & 12.5 & 33.33 & 4.17 & 12.5 & $100 \%$ & \\
\hline
\end{tabular}


Note: Each question has a 6-point Likert scale options (SA-strongly agree, A-agree, N-neutral, Ddisagree, SD-strongly disagree, NA-not applicable) and the responses are assigned the value as $(6,5$, $4,3,2,1)$ respectively.

The fact that all students who were able to successfully explore $\mathrm{Cl}$ were positive about the experience is also very encouraging. Additionally, the finding that some students had difficulty learning to use the environment and its associated software is not unexpected, considering the known steepness of the learning curve, especially for users not already familiar with online interactive gaming (see "Research design" above). Survey results showed that 11 students (39\%) had some experience with online gaming, while the majority lacked this experience. Tellingly, all six students who indicated moderate to high levels of frustration with technical elements also belonged to this majority group who had either only played offline games such as card games, or else did not play computer games at all.

The sample size and the focus of the questions asked do not permit the researchers to propose an explanation for why these three students found the frustrations of engaging with $\mathrm{Cl}$ insurmountable, beyond speculating that the "self-service" model of technical instruction deployed in the study (while very cost-effective in terms of staff time) was perhaps insufficient for students whose relevant computer experience was low. The corollary to this is that, for most students, the self-service model was effective, and could be retained in similar deployments with the potential addition of targeted support for students who lack experience with interactive online environments.

\section{Themes}

In addition to informing the interpretation of the quantitative questions, as discussed earlier, thematic analysis was also undertaken to identify the primary and recurring matters mentioned by users who elected to respond when asked if there was anything else they wanted to tell researchers about their experience in $\mathrm{Cl}$. The data collected was freeform text, and was largely unprompted, being elicited by the question "Is there anything else you want to tell us about your experience with Chinese Island?" Accordingly, not all points raised in the texts were directly relevant to the research questions.

Twelve participants supplied responses to this question, and from these responses 42 individual comments were identified. From these, 33 unique codes were generated, representing a total of 55 codes (some comments were allocated more than one code). Some themes were identified that fell outside the scope of the research questions, such as discussion of technical or pedagogical matters. Several remarks of approval or disapproval were made, but many were not specific, and could only be used for guidance in determining approval or frustration, as discussed above.

The remaining comments were subjected to an additional round of reflection and analysis, resulting in the identification of three themes: interactivity and interaction, psychological and experiential factors, and exploration. These themes reflected matters pertinent to the investigation that had been sufficiently salient for respondents to mention them without being directly prompted, and thus can be seen as strong indications of the areas of interest for this group of highly-motivated Chinese learners when engaging with $\mathrm{Cl}$. Finally, the raw text data were reviewed using these themes as a framework to verify that the tenor of the original comments was adequately encapsulated by the themes.

\section{Interactivity and interaction}


Twelve instances of this theme were identified. Students wrote about their desire to interact with objects in $\mathrm{Cl}$, with NPCs, and with other online users, about their disappointment when they weren't able to engage in the kind of interaction they had imagined (e.g., expressing the wish "to interact with other people in the game"), and about how Cl's interactivity was helpful in language-learning.

\section{Psychological and experiential factors}

Seven instances of this theme were identified and were uniformly positive in tone. Students wrote about gaining confidence and overcoming timidity in communication and expressed strong appreciation for the realism of the virtual environment, mentioning, for example, "the feeling of being immersed in real-life, Chinese cultural situations."

\section{Exploration}

Five instances of this theme were identified and were largely negative in tone. Some students expressed appreciation of the learning experiences that they gained through unguided free-roaming after completing the initial activity they had been directed towards, while others suggested that they would have preferred additional explicit direction-suggesting that students preferred engaging with assigned tasks, and under their own initiative did not discover much of the other linguistic and cultural material embedded in the environment. These students perhaps overlooked the direction to undertake the assigned activity and relied on encountering content within the "game" by trial and error, creating a wish for something "to guide the player through learning how to [interact]." This may indicate a difficulty with self-service delivery of instruction, because of the diverse range of points that need to be made salient for the user.

\section{Discussion}

Participants had an intrinsic motivation to participate in $\mathrm{Cl}$ because they were enthusiastic learners, but did not all have specific motivation to engage in "gaming" as a study activity. However, the findings above will have relevance to broader student groups in implementations where extrinsic structural motivations exist - for example, if participation counts in some way towards fulfilment of a course requirement. Accordingly, so long as sufficient incentives are available, it is reasonable to expect similar levels of acceptance in other student bodies of similar demographic structure especially if targeted support is made available for students who have had little exposure to immersive online environments. Furthermore, in the case of the majority of learners who do not need such assistance, there are grounds to believe that the commitment of extensive time in class preparing students can be effectively avoided by the provision of electronic materials, primarily in text format, with screenshot images added as illustrations of what students can expect to see.

Turning to the qualitative data, the investigation found that students, once appropriately motivated to participate, will look for interaction (with objects, NPCs, and/or other online users), and will highly value the experiential aspects of immersion (such as the "feeling" of being there, or of transacting communicative tasks). Conversely, students are likely to be de-motivated by the feeling of too much freedom, and will benefit from extended scaffolding from instructors around the purpose of their interaction on any particular visit to the environment (such as being given a task or challenge to complete for each occasion when they log in).

\section{Conclusion and future direction}

As shown in the discussion, the results obtained in this study proved this resource to be beneficial to CFL learners' Chinese learning particularly through interactivities and interactions with objects and NPCs on $\mathrm{Cl}$, which reflect 'real language' and 'real life' in the target language environment. 
Furthermore, this resource has also helped to promote high-quality Chinese language learning experiences at both beginner and intermediate level, and particularly provided a strong foundation for extension to off-campus students. In the context of this university, then, the deployment of $\mathrm{Cl}$ into the Chinese program would indeed be feasible and justifiable, providing adequate incentivisation and support are in place. In terms of how the learners experienced the resource, the opportunity to vicariously "live" in a Chinese environment, as well as to gain enactive mastery experiences that build confidence in the learner's ability to engage in communication, were both prominently positive aspects of $\mathrm{Cl}$ in the eyes of participants, adding experiential dimensions of learning that did not already exist in the program.

Regarding its pedagogical implications, the insights drawn from this study have allowed the Chinese program to adapt to a future of blended delivery mode through developing a model sustainable for language teaching at this university. The model should be flexible and effective in terms of supplementing classroom teaching of Chinese language, particularly at the beginning level. For example, integrating 3D MUVWs in CFL could be a potential approach to using technology to enrich learning experiences in a Chinese language classroom and beyond. Broad optimism exists in the wealth of literature about the potential of VWs for the delivery of learning activities based on TBLL (Ishak \& Seedhouse, 2012). Additionally, the 3Is (immersion, imagination, and interaction) of SL have proven to be beneficial to learners' foreign language learning motivation (Henderson et al., 2012; Lan, 2015). Furthermore, being the first project ever to adapt this resource for Chinese language students and to research the efficacy of such an approach outside this major urban Australian university, it could be a significant step towards fostering an authentic language learning environment that embeds extant technologies to provide experiential learning specifically tailored to language learning. Meanwhile, by adding a piece of empirical evidence to broaden the understanding of 3D authentic and immersive environments for CFL learners, it is hoped that this study will cast light on exploring an innovative and integrated approach, which can transform CFL teaching and learning for more efficiency and learner autonomy.

From the current study, it was found that more research is needed to establish the "consistently successful premises" by which such interactive elements can be integrated into university courses, rather than simply added as an additional task for learners (McGee \& Reis, 2012). In relation to future research, possible directions could be to conduct an experimental study by developing pedagogically-sound tasks to motivate students to perform them in VWs. To that end, educators must take into account learner background, pedagogical issues, and teaching goals (Chen, 2010). In addition, more research is also required to better understand learner-to-learner, learner-toinstructor, and learner-to-content engagement strategies in VWs (Moore, 1993). Thus, the investigative focus of future projects could be on how VWs may have affected students' beliefs about their own ability to undertake further study in Chinese, especially in-country study, as well as seeking specific feedback about how VWs mesh with students' overall experience as CFL learners. It is worth mentioning that this study's results strongly suggest that more planning is required to ensure the design of meaningful learning activities that can better support the formal university curriculum.

\section{Acknowledgement}

This work was supported by the University of Tasmania under Teaching Development Grant.

\section{Disclosure statement}

No potential conflict of interest was reported by the authors. 


\section{Notes on contributors}

Yanjun Wang is a lecturer in Chinese in the School of Humanities at the University of Tasmania in Australia. Her research interest is the integration of innovative and flexible teaching and learning resources to enhance students' learning experiences, particularly focusing on absolute beginners.

Scott Grant is a lecturer in Chinese at the School of Languages, Literatures, Cultures and Linguistics, Faculty of Arts, Monash University in Australia. He is the creator of Chinese Island and the Chinese Island approach to experiential learning of Chinese as a Foreign Language. He has published extensively on language teaching and learning in 3D multiuser virtual worlds.

Matthew Grist is a PhD student in the School of Humanities at the University of Tasmania. He is researching learner self-efficacy beliefs in Second Language Acquisition learners located in an English cultural and linguistic background.

\section{ORCID}

Yanjun Wang (iD) https://orcid.org/0000-0003-0159-8828

Scott Grant (D) https://orcid.org/0000-0002-2413-288X

Matthew Grist (D) https://orcid.org/0000-0001-6217-5066

\section{References}

Austin, M. J., \& Rust, D. Z. (2015). Developing an Experiential Learning Program: Milestones and Challenges. International Journal of Teaching and Learning in Higher Education, 27(1), 143153.

Blake, R. (2017). Distance Education for Second and Foreign Language Learning. In S. L. Thorne \& S. May (Eds.), Language, Education and Technology (pp. 157-168). Cham: Springer International Publishing.

Brannan, J. D., White, A., \& Bezanson, J. L. (2008). Simulator effects on cognitive skills and confidence levels. The Journal of nursing education, 47(11), 495-500. doi:10.3928/0148483420081101-01

Brown, H. D. (2000). Principles of language learning and teaching. New York, NY: Pearson Education.

Burch, G. F., Giambatista, R., Batchelor, J. H., Burch, J. J., Hoover, J. D., \& Heller, N. A. (2019). A MetaAnalysis of the Relationship Between Experiential Learning and Learning Outcomes. Decision Sciences Journal of Innovative Education, 17(3), 239-273. doi:10.1111/dsji.12188

Casanave, C. P. (2004). Controversies in second language writing: Dilemmas and decisions in research and instruction. Ann Arbor, MI: University of Michigan Press.

Chen, D. (2010). Enhancing the learning of Chinese with Second Life. Journal of Technology and Chinese Language Teaching 1(1), 14-30.

Chun, D. M. (1998). Using computer-assisted class discussion to facilitate the acquisition of interactive competence. In J. Swaffar, S. Romano, P. Markley, \& K. Arens (Eds.), Language Learning Online: Theory and Practice in the ESL and L2 computer classroom (pp. 57-80). Austin: Labyrinth.

Grant, S., Huang, H., \& Pasfield-Neofitou, S. (2013). Language learning in virtual worlds: The role of FLA and technical anxiety. Journal of Virtual Worlds Research 6(1), 1-9.

Group of Eight. (2007). Languages in crisis: A rescue plan for Australia. Manuka: Group of Eight Australia.

Henderson, M., Huang, H., Grant, S., \& Henderson, L. (2012). The impact of Chinese language lessons in a virtual world on university students' self-efficacy beliefs. Australasian Journal of Educational Technology, 28(3), 400-419. doi:10.14742/ajet.842 
Hymes, D. (1992). The concept of communicative competence revisited. In M. Putz (Ed.), Thirty years of linguistic evolution: studies in honour of Rene Dirven on the occasion of his sixtieth birthday (pp. 31-58). Amsterdam: John Benjamins.

Ishak, N. F., \& Seedhouse, P. (2012). Interactive Digital Kitchen: The impact on language learning. Paper presented at the EUROCALL, University of Gothenburg, Sweden.

Jarmon, L., Traphagan, T., Mayrath, M., \& Trivedi, A. (2009). Virtual world teaching, experiential learning, and assessment: An interdisciplinary communication course in Second Life. Computers \& Education, 53(1), 169-182. doi:10.1016/j.compedu.2009.01.010

Johnson, K. (2008). An introduction to foreign language learning and teaching (2nd ed.). Oxford, England: Routledge.

Knutson, S. (2003). Experiential learning in second-language classrooms. TESL Canada Journal, 20(2), 52. doi:10.18806/tesl.v20i2.948

Kohonen, V. (1992). Experiential language learning: Second language learning as cooperative learner education. In D. Nunan (Ed.), Collaborative language learning and teaching (pp. 14-39). Cambridge CUP.

Kolb, D. (2014). Experiential learning: Experience as the source of learning and development (2nd ed.). New York, NY: Pearson Education.

Lan, Y.-J. (2015). Contextual EFL learning in a 3D virtual environment. Language Learning \& Technology 19(2), 16-31.

Lan, Y.-J., \& Ling, Y.-T. (2016). Mobile seamless technology enhanced CSL oral communication. Journal of Educational Technology \& Society, 19, 335-350.

Machado, L., Klein, A., Freitas, A., Schlemmer, E., \& Pedron, C. (2016). The Use of Virtual Worlds for Developing Intercultural Competences. International Journal of Information and Communication Technology Education (IJICTE), 12(3), 51-64. doi:10.4018/IJICTE.2016070105

McGee, P., \& Reis, A. (2012). Blended course design: A synthesis of best practices. Journal of Asynchronous Learning Networks, 16, 7-22.

Moloney, R., \& Xu, H. L. (2016). Exploring innovative pedagogy in the teaching and learning of Chinese as a foreign language. Singapore: Springer.

Moore, K. J. (1993). Three types of interaction. In K. Harry, M. John, \& D. Keegan (Eds.), Distance education theory (pp. 19-24). New York, NY: Routledge.

Moreno-López, I., Ramos-Sellman, A., Miranda-Aldaco, C., \& Gomis Quinto, M. T. (2017). Transforming Ways of Enhancing Foreign Language Acquisition in the Spanish Classroom: Experiential Learning Approaches. Foreign Language Annals, 50(2), 398-409. doi:10.1111/flan.12267

Navarre, A. (2019). Technology-enhanced teaching and learning of Chinese as a foreign language. New York, NY: Routledge.

Orton, J. (2010). The current state of Chinese language education in Australian schools. Carlton, Vic: Education Services Australia

Orton, J., \& Scrimgeour, A. (2019). Teaching Chinese as a second language: The way of the learner. New York and London: Routledge.

Pasfield-Neofitou, S., Grant, S., \& Huang, H. (2016). Task-based Chinese as a foreign language (CFL) in Second Life for beginner learners and educators. In R. Moloney \& H. L. Xu (Eds.), Exploring innovative pedagogy in the teaching and learning of Chinese as a foreign language (pp. 213233). Singapore Springer.

Reinders, H. (2010). Towards a classroom pedagogy for learner autonomy: A framework of independent language learning skills. Australian Journal of Teacher Education (Online), 35(5), 40-55. doi:10.14221/ajte.2010v35n5.4

Rubesch, T., \& McNeil, M. (2010). Online versus face-to-face: Motivating and demotivating factors in an EAP writing course. The JALT CALL Journal, 6(3), 235-250. doi:10.29140/jaltcall.v6n3.103

Scarino, A., \& Liddicoat, A. J. (2009). Teaching and learning languages: A guide. Carlton South, Australia: Curriculum Corporation. 
Schott, C., \& Marshall, S. (2018). Virtual reality and situated experiential education: A conceptualization and exploratory trial. Journal of Computer Assisted Learning, 34(6), 843852. doi:10.1111/jcal.12293

Sharifi, N., \& Shariati, M. (2017). Using experiential learning to enhance students' foreign language proficiency. Translation Journal(July 2017). Retrieved from https://translationjournal.net/July-2017/using-experiential-learning-to-enhance-studentsforeign-language-proficiency.html

Thomas, M., \& Reinders, H. (2012). Task-based language learning and teaching with technology. London and New York: Continuum.

Tranter, B. (2013). Sampling. In M. Walter (Ed.), Social Research Methods South Melbourne, Australia: Oxford. 